\title{
Short communication: Behavioral evaluation of the analgesic effect of flunixin meglumine in lame dairy cows
}

\author{
S. A. Wagner, ${ }^{* 1}$ J. M. Young, ${ }^{*}$ J. K. Tena, $†$ and B. H. Manningt \\ *Department of Animal Sciences, North Dakota State University, Fargo 58108 \\ †Zoetis Inc., Kalamazoo, Ml 49007
}

\begin{abstract}
The objective of this study was to evaluate the effect of flunixin meglumine treatment on lameness pain in dairy cows. Twenty-four lactating Holstein cows were enrolled in the study based on visual observation of abnormal locomotion. The primary measurement endpoint was weight-shifting between the rear limbs. Weight-shifting was calculated as the standard deviation of the weight borne on the rear limbs over a $15 \mathrm{~min}$ period; this value correlates directly with lameness pain in dairy cows. After collecting baseline weight-bearing data, we randomly assigned cows to 1 of 2 treatment groups: $2.2 \mathrm{mg} / \mathrm{kg}$ body weight flunixin meglumine $(2$ $\mathrm{mL} / 45 \mathrm{~kg}$ ) or an equivalent volume of isotonic sterile saline solution. Weight-bearing data were collected from each cow at 2, 6, 12, and $24 \mathrm{~h}$ after a single intravenous drug treatment. Mean locomotion scores over the $2 \mathrm{~d}$ before treatment were $2.38 / 5$ in the flunixin-treated group and $2.43 / 5$ in the saline-treated control group; these values were not significantly different. Weightshifting values were also not significantly different on either pretreatment day. Cows treated with flunixin meglumine showed significantly less weight-shifting between the rear limbs at 6,12 , and $24 \mathrm{~h}$ after treatment compared with saline-treated controls, providing evidence that flunixin meglumine alleviates lamenessassociated pain.
\end{abstract}

Key words: analgesia, flunixin, lameness, pain

\section{Short Communication}

Lameness is a common painful condition in dairy cows; recently published studies of North American dairy herds have returned estimates between $9.6 \%$ and $15 \%$ for the prevalence of lameness (Cook et al., 2016; King et al., 2016; Westin et al., 2016; Adams et al., 2017). Alleviating the pain of lameness can improve

Received November 18, 2016.

Accepted May 5, 2017.

${ }^{1}$ Corresponding author: Sarah.Wagner@ndsu.edu animal welfare, but no drugs have been approved by the United States Food and Drug Administration for the relief of pain in cattle. In horses, the non-steroidal anti-inflammatory drug (NSAID) flunixin meglumine is approved to treat pain due to musculoskeletal conditions and visceral pain due to colic (Intervet/Merck Animal Health, 2011). Flunixin meglumine is approved for use in cattle to treat inflammation and pyrexia associated with certain conditions, and NSAIDs such as flunixin meglumine are often used as extra-label therapy for pain relief in cattle (Fajt et al., 2011).

In a previous study, flunixin meglumine was administered to lame and non-lame dairy cows at the time of hoof trimming, and this combination of treatments did not affect lameness, as measured by visual observation (i.e., locomotion scoring) or by weight distribution (Chapinal et al., 2010a). The objective of this study was to evaluate the efficacy of flunixin meglumine treatment without concurrent hoof trimming for the alleviation of lameness pain in lactating dairy cows.

We selected lactating Holstein dairy cows for the study based on the presence of abnormal locomotion consistent with lameness and the absence of other health issues. Cows were enrolled weekly in cohorts of 2 or 4 and randomized to treatment groups blocked on enrollment cohort. Within each enrollment cohort, cows were randomly assigned to a treatment group, with equal allocation to each group ( $\mathrm{n}=12$ per group) using SAS (SAS Institute, Inc., Cary, NC).

Cows in the drug treatment group (FLU) received a single intravenous injection of $2.2 \mathrm{mg} / \mathrm{kg} \mathrm{BW}(2 \mathrm{~mL} / 45$ $\mathrm{kg} \mathrm{BW}$ ) flunixin meglumine (Banamine; Merck Animal Health, Madison, NJ). Cows in the placebo treatment group (SAL) received a single intravenous injection of isotonic sterile saline solution at the same volume dosage as the FLU group.

On each of the $2 \mathrm{~d}$ before treatment, we recorded baseline locomotion and weight-shifting data. A digital camera (Canon Power Shot; Canon USA, Melville, NY) was used to record each cow walking at least 5 paces, and these recordings were used by a masked, trained observer to assign a locomotion score of 1 to 5 , as described by Flower and Weary (2006). A score of 1 was 
associated with no lameness, and a score of 5 indicated severe lameness. Scores were assigned in intervals of 0.5 points.

We recorded weight distribution using a 4-platform scale (Pacific Industrial Scale, Richmond, BC, Canada) with a standard head catch, which independently records the weight borne on each limb approximately 11 times per second, using procedures described by Chapinal et al. (2010b). Cows were acclimated to the 4-platform scale before data collection. At each datacollection point, cows stood on the scale for 3 sessions of 5 min each. Between sessions, cows were walked off the scale from the front, and then walked back onto the scale from the rear. Data recorded during defecation, urination, or placement of any hoof on the wrong platform were deleted from the analyses. We calculated the mean and standard deviation (SD) of the weight borne on each limb during each 5 min session, and averaged the SD values for the rear limbs. We then averaged the average SD values further across the 3 sessions to determine the overall weight-shifting value (SHFT) for that data-collection time point.

Then, $24 \mathrm{~h}$ after the second collection of baseline data as described above, cows received their assigned treatments. Immediately after morning milking, each cow was treated with flunixin meglumine or isotonic sterile saline solution. Treatment was followed by collection of weight-distribution data $2,6,12$, and $24 \mathrm{~h}$ after treatment. Each cow was examined by a professional hoof trimmer $24 \mathrm{~h}$ to $48 \mathrm{~h}$ after the final data collection, and observed lesions were recorded.

We developed the summary and conducted the data analysis using SAS (SAS Institute, Inc.). As described above, the primary outcome variable was the SD of the mean weight borne on the rear limbs averaged over three 5-min sessions (SHFT). We analyzed the SHFT data using a general linear mixed model with repeated measures. The model included the fixed effects of treatment, time, and the treatment $\times$ time interaction. Random effects included block, animal within block and treatment, and error. A repeated effect with subject cow was included in the model. Different covariance matrices were tested and evaluated. We chose the best covariance matrix based on Akaike's and Bayesian information criteria. If the effects of treatment or treatment $\times$ time interaction were significant $(P<0.05)$, we performed treatment comparisons at each time point at the $5 \%$ level of significance (2-sided).

Locomotion scoring data are presented in Figure 1. Mean baseline locomotion scores $48 \mathrm{~h}$ before treatment were $2.33 \pm 0.14$ in the FLU group and $2.46 \pm 0.14$ in the SAL group. The day before treatment, mean locomotion scores were $2.42 \pm 0.13$ in the FLU group and $2.42 \pm 0.12$ in the SAL group. Locomotion scores

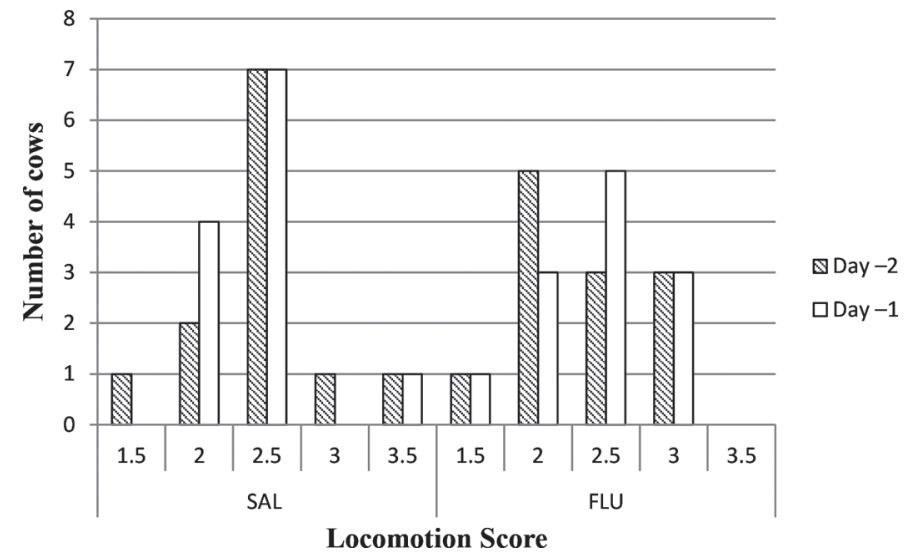

Figure 1. Distribution of pretreatment (d -2 and -1$)$ locomotion scores. $\mathrm{SAL}=$ cows treated with $2 \mathrm{~mL}$ of isotonic saline solution $/ 45$ $\mathrm{kg}$ of BW (n=12); FLU = cows treated with a single dose of $2.2 \mathrm{mg}$ of flunixin meglumine $/ \mathrm{kg}$ of $\mathrm{BW}(2 \mathrm{~mL} / 45 \mathrm{~kg} ; \mathrm{n}=12)$.

were not significantly different between groups on either pretreatment day $(P>0.05$ both days).

Weight-shifting data, measured as SHFT, are shown in Figure 2. Values for SHFT on days -2 and -1 before drug treatment were $27.1 \pm 2.5 \mathrm{~kg}$ and $28.0 \pm 3.0 \mathrm{~kg}$ in the SAL group and $24.7 \pm 1.9 \mathrm{~kg}$ and $25.2 \pm 2.4$ in the FLU group. These values were not significantly different between groups on day $-2(P=0.52)$ or day $-1(P$ $=0.46)$. Although SHFT values were not statistically different between groups before treatment, they were numerically different; therefore, they were included as a cofactor in post-treatment statistical analyses. At 2 $\mathrm{h}$ after treatment, SHFT values in the SAL and FLU groups were not different $(29.6 \pm 2.5 \mathrm{~kg}$ and $23.7 \pm$ $2.5 \mathrm{~kg}$, respectively, $P=0.13)$. At $6 \mathrm{~h}, 12 \mathrm{~h}$, and 24 $\mathrm{h}$, SAL cows exhibited more weight-shifting behavior than FLU cows. The SHFT after treatment in the SAL and FLU groups were $31.6 \pm 2.6 \mathrm{~kg}$ and $23.4 \pm 2.1 \mathrm{~kg}$, respectively, $6 \mathrm{~h}$ after treatment $(P=0.01) ; 33.9 \pm$ $2.7 \mathrm{~kg}$ and $25.1 \pm 2.0 \mathrm{~kg}$, respectively, $12 \mathrm{~h}$ after treatment $(P<0.01)$; and $32.3 \pm 3.4 \mathrm{~kg}$ and $22.6 \pm 2.6 \mathrm{~kg}$, respectively, $24 \mathrm{~h}$ after treatment $(P<0.01)$.

In both treatment groups, the 2 daily pretreatment SHFT values were not different $(P>0.05$ for both). In the FLU group, differences in weight-shifting behavior were not significant among days $(P>0.05$ for all between-day comparisons). In the SAL group, SHFT values were not different between baseline and $2 \mathrm{~h}(P$ $>0.05)$, but weight-shifting was significantly greater at 6,12 , and $24 \mathrm{~h}$ after treatment than at baseline or $2 \mathrm{~h}$ after treatment ( $P<0.05$ for all comparisons).

Lesions observed in enrolled cows are described in Table 1. In both treatment groups, the most common lesions were sole lesions, including sole/toe hemorrhage, sole ulcer, and white line disease. After sole lesions, 
the most commonly observed lesion in both groups was digital dermatitis. The distribution of lesions was similar between groups, with sole lesions on 1 or both rear feet in 4 SAL cows and 3 FLU cows, digital dermatitis on 1 or both rear feet in 2 SAL cows and 3 FLU cows, and a lesion of each type on each rear foot in $1 \mathrm{cow}$ from each group. One cow in the SAL group and 3 cows in the FLU group had no visible lesions. Lesion data were not recovered for 2 cows in each treatment group. The lesions found in this study group were typical of lame dairy cows in North America; sole ulcers, white line disease, and digital dermatitis are the most commonly observed lesions (Solano et al., 2016). Whether flunixin meglumine alleviates pain in dairy cows with less common causes of lameness is not known.

The relationship between observable hoof lesions and locomotion is inconsistent. When O'Callaghan et al. (2003) performed a study in which 345 cows were evaluated for locomotion and examined for hoof lesions, they reported that, "Although severe lesions were usually associated with high scores, some cows with severe foot lesions did not show obvious lameness." In light of the pathophysiology of sole lesions - the changes that produce them occur long before lesions are visible, and visible lesions may take months to resolve - it is not surprising that pain and associated behavioral changes do not correlate exactly with the type and prevalence of lesions. It is also likely that different cows have different perceptions of pain and different levels of stoicism.

When Sprecher et al. (1997) evaluated cows based on a 5-point locomotion scale, they found that deleterious effects on reproduction and an increase in culling risk were associated with scores of 2 out of 5 or higher. In that study, a score of 2 was described as an arched back

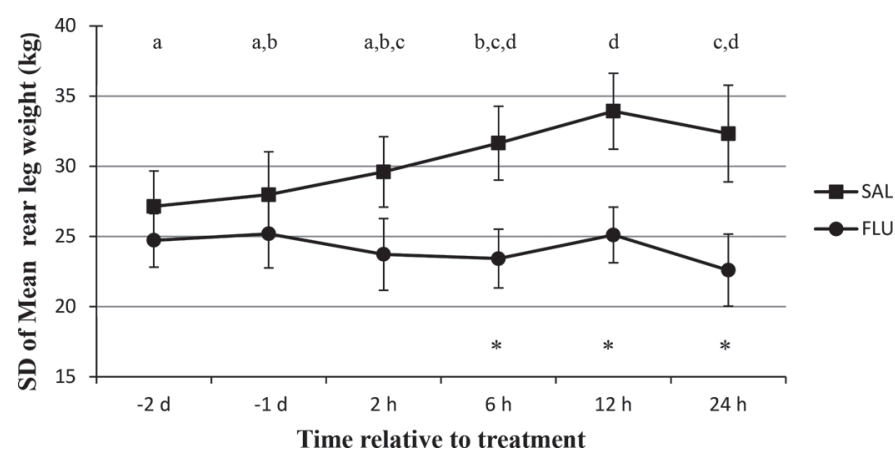

Figure 2. Standard deviation of the mean of rear limb weight over time (SHFT) relative to treatment. SAL $=$ cows treated with $2 \mathrm{~mL}$ of isotonic saline solution $/ 45 \mathrm{~kg}$ of BW $(\mathrm{n}=12) ; \mathrm{FLU}=$ cows treated with a single dose of $2.2 \mathrm{mg}$ of flunixin meglumine $/ \mathrm{kg}$ of BW $(2 \mathrm{~mL} / 45$ $\mathrm{kg} ; \mathrm{n}=12$ ), Values shown are group means, with bars representing the SEM. Asterisks $(*)$ indicate time points where group means differed $(P$ $<0.05)$. Group means over time did not differ in the FLU group. Time points with the same letter $(\mathrm{a}-\mathrm{d})$ were the same in the SAL group.
Table 1. Distribution of claw-horn and soft-tissue lesions across treatment groups ${ }^{1}$

\begin{tabular}{lcc}
\hline Lesion & SAL & FLU \\
\hline Sole lesion, 1 rear & 3 & 1 \\
Sole lesion, both rear & 1 & 2 \\
Digital dermatitis, 1 rear & 1 & 2 \\
Digital dermatitis, both rear & 1 & 1 \\
Digital dermatitis, 1 rear and sole lesion other rear & 1 & 1 \\
Old injury with atypical hoof growth, 1 rear & 1 & 0 \\
Sole lesion and digital dermatitis, same rear & 1 & 0 \\
No visible lesions & 1 & 3 \\
No data recorded & 2 & 2 \\
Front-limb lesions also observed & 1 & 1 \\
\hline
\end{tabular}

${ }^{1} \mathrm{SAL}=$ cows treated with $2 \mathrm{~mL}$ of isotonic saline solution $/ 45 \mathrm{~kg}$ of $\mathrm{BW}(\mathrm{n}=12) ; \mathrm{FLU}=$ cows treated with a single dose of $2.2 \mathrm{mg}$ of flunixin meglumine $/ \mathrm{kg}$ of $\mathrm{BW}(2 \mathrm{~mL} / 45 \mathrm{~kg} ; \mathrm{n}=12)$.

posture with otherwise normal locomotion. Cows were not examined for lesions. Abnormal locomotion is a sensitive method of detecting cows with lameness that has adverse effects on function and survival, independent of the presence or type of lesions. Consequently, the distribution of pretreatment locomotion scores is more critical than lesion type and prevalence when evaluating the equivalence of pretreatment lameness between treatment groups. Because of the importance of locomotion scores for establishing the pretreatment status of the cows, we obtained 2 baseline observations of locomotion.

On the day before treatment, 11 of 12 cows in each treatment group had baseline locomotion scores between 2 and 3. In each group, the sole outlier from that range was balanced by the distribution of the cows within the range. Group mean locomotion scores matched exactly (2.42; standard error of the mean, 0.01$)$ on the day before treatment. Pretreatment scores in both groups were consistent with the presence of mild to moderate lameness.

Weight-shifting between the rear limbs in dairy cows has been validated as an objective, quantitative method for measuring foot discomfort (Neveux et al., 2006); distinguishing between lame and non-lame cows (Pastell and Kujala, 2007; Rushen et al., 2007); detecting the alleviation of lameness pain using a local anesthetic (Rushen et al., 2007); and evaluating the analgesic effects of the NSAID ketoprofen (Chapinal et al., 2010b). In the present study, lame dairy cows treated with a single intravenous injection of the NSAID flunixin meglumine had less weight-shifting on their rear limbs at 6,12 , and $24 \mathrm{~h}$ after treatment than control cows treated with sterile saline solution. Differences in weight-shifting behavior between FLU and SAL cows after treatment were due primarily to increased shifting behavior in SAL cows over time. This may be explained by the method used to evaluate weight-shifting 
behavior. For each data-recording session, cows stood on the scale for at least $15 \mathrm{~m}$. Including time spent collecting the cow from her home pen, walking her, keeping notes, adjusting her posture if necessary (cows occasionally placed 2 hooves on the same platform), and waiting during periods of elimination or distraction, each data-collection session lasted 30 min or more. Scale data-collection activities increased the time cows spent standing each day, especially on the day of treatment, when scale data were collected 3 times. One of the key contributors to lameness in dairy cows is time spent standing on hard surfaces (Shearer et al., 2013). It is likely that the SAL cows experienced more pain over time because of the increased time spent standing on the day of treatment, and treatment with flunixin meglumine eliminated the irritating effects of increased time spent standing. In an earlier study, in which cows were evaluated once per day after treatment with the NSAID ketoprofen, cows in the treated group showed decreased weight-shifting compared with untreated cows and compared with baseline values; weight-shifting in untreated cows was unchanged over the study period (Chapinal et al., 2010b). A comparison of the outcomes between the present study and Chapinal et al. (2010b) supports the interpretation that the pattern of within-group weight-shifting over time in this study is attributable to the increased amount of time cows spent standing during the study.

The diminished weight-shifting behavior in FLU cows compared with SAL cows in the present study was in contrast to the results of an earlier study that evaluated the effects of flunixin meglumine in dairy cows (Chapinal et al., 2010a). In that study, hoof trimming and flunixin meglumine treatment were performed concurrently and the authors observed no clear effect of either treatment. Hoof trimming alone is known to increase locomotion scores, suggesting that hoof trimming itself increases lameness-associated pain (Van Hertem, et al., 2014). In the present study, the potentially confounding effect of concurrent hoof trimming was removed, and we observed significant analgesic effects of flunixin meglumine treatment.

The onset of analgesia in the present study appeared to be longer than $2 \mathrm{~h}$ but less than $6 \mathrm{~h}$. We found no published reports of the time to onset of analgesic action of NSAIDs in cattle, and little information is available about analgesic onset times following NSAID treatment in other veterinary species. A study examining mechanically induced lameness in horses found that lameness scores were significantly lower in horses treated with flunixin meglumine than in horses treated with saline by $1.3 \mathrm{~h}$ after treatment, when horses were evaluated every $20 \mathrm{~min}$ (Foreman and Ruemmler, 2011). In that study, flunixin meglumine treatment was administered just $1 \mathrm{~h}$ after lameness was induced by applying a screw to the sole of the horses' hooves. The reason for the longer apparent time to onset of analgesia in the present study is not known; possible explanations include species differences in timing to achieve therapeutic levels of drug in body tissues, or differences in the drug's effect in chronic versus acute conditions. It is also possible that we may have detected a treatment difference at $2 \mathrm{~h}$ after treatment in the present study if we had enrolled more cows.

The duration of treatment effect observed in the present study outlasted the expected presence of therapeutic levels of the drug and its metabolite in the plasma of treated cows. A recent study reported on the pharmacokinetics of flunixin meglumine $(2.2 \mathrm{mg} / \mathrm{kg})$ and its primary metabolite, 5-hydroxy flunixin, following intravenous administration to healthy dairy cows and cows with mastitis. In healthy cows the elimination half-life was $3.68 \mathrm{~h}$, and no drug or metabolite was detected in plasma $18 \mathrm{~h}$ after treatment (Kissell et al., 2015). In contrast, in cows with mastitis, the elimination half-life for flunixin meglumine and its metabolite was $4.35 \mathrm{~h}$, and the drug or its metabolite was detectable in the plasma $24 \mathrm{~h}$ after treatment. The authors hypothesized that drug elimination was delayed in cows with mastitis because of slower drug metabolism in the liver as a result of inflammatory mediators produced as a part of the immune response to mastitis. Chronically lame cows may also have slower drug metabolism in the liver as a result of inflammation, resulting in slower clearance of the drug from the body. Indeed, NSAIDs often appear to have analgesic effects that last beyond the presence of measurable drug levels in the plasma. Because inflammation produces increased blood flow and blood vessel permeability, NSAIDs are well distributed to sites of inflammation. High levels of protein binding (Brune, 2007) allow NSAIDs to persist at sites of tissue inflammation even though they are relatively rapidly cleared from the blood plasma. Some combination of altered drug metabolism and tissue persistence probably contributed to the apparent extended duration of analgesia associated with flunixin meglumine in the present study.

In summary, in cows with mild to moderate lameness, a single intravenous dose of $2.2 \mathrm{mg} / \mathrm{kg}$ of $\mathrm{BW}$ flunixin meglumine provided analgesia from 6 to $24 \mathrm{~h}$ after treatment, compared with saline-treated controls. Treatment differences appeared to be due to an exacerbation of lameness pain due to extended standing times in control cows and a protective effect against the detrimental effects of standing on hard surfaces in flunixin meglumine-treated cows. Despite flunixin meglumine's observed elimination half-life of less than $5 \mathrm{~h}$ in cattle with inflammatory conditions, we detected 
the effects of a single IV dose until the end of the $24 \mathrm{~h}$ post-treatment observation period.

\section{ACKNOWLEDGMENTS}

Funding for this project was provided by Zoetis Inc. (Kalamazoo, MI). The authors thank the Schlauderaff Dairy (Detroit Lakes, MN), Matt Larson of Larson Hoof Trimming (Detroit Lakes, MN), and Leah Maertens of North Dakota State University. Special thanks also go to Anne Marie de Passillé and Jeffrey Rushen of the University of British Columbia (Vancouver, BC, Canada).

\section{REFERENCES}

Adams, A. E., J. E. Lombard, C. P. Fossler, I. N. Román-Muñiz, and C. A. Kopral. 2017. Associations between housing and management practices and the prevalence of lameness, hock lesions, and thin cows on US dairy operations. J. Dairy Sci. 100:2119-2136.

Brune, K. 2007. Persistence of NSAIDs at effect sites and rapid disappearance from side-effect compartments contributes to tolerability. Curr. Med. Res. Opin. 23:2985-2995.

Chapinal, N., A. M. De Passillé, J. Rushen, and S. Wagner. 2010b. Automated methods for detecting lameness and measuring analgesia in dairy cattle. J. Dairy Sci. 93:2007-2013.

Chapinal, N., A. M. De Passillé, J. Rushen, and S. A. Wagner. 2010a. Effect of analgesia during hoof trimming on gait, weight distribution, and activity of dairy cattle. J. Dairy Sci. 93:3039-3046.

Cook, N. B., J. P. Hess, M. R. Foy, T. B. Bennett, and R. L. Brotzman. 2016. Management characteristics, lameness, and body injuries of dairy cattle housed in high-performance dairy herds in Wisconsin. J. Dairy Sci. 99:5879-5891.

Fajt, V. R., S. A. Wagner, and B. Norby. 2011. Analgesic drug administration and attitudes about analgesia in cattle among bovine practitioners in the United States. J. Am. Vet. Med. Assoc. 238:755-767.

Flower, F. C., and D. M. Weary. 2006. Effect of hoof pathologies on subjective assessments of dairy cow gait. J. Dairy Sci. 89:139-146.
Foreman, J. H., and R. Ruemmler. 2011. Phenylbutazone and flunixin meglumine used singly or in combination in experimental lameness in horses. Equine Vet. J. Suppl. (40):12-17. https://doi. org/10.1111/j.2042-3306.2011.00485.x.

Intervet/Merck Animal Health, 2011. Banamine package insert. Intervet/Merck Animal Health, Madison, NJ.

King, M. T. M., E. A. Pajor, S. J. LeBlanc, and T. J. DeVries. 2016 Associations of herd-level housing, management, and lameness prevalence with productivity and cow behavior in herds with automated milking systems. J. Dairy Sci. 99:9069-9079.

Kissell, L. W. T. L. Leavens, R. E. Baynes, J. E. Riviere, and G. W. Smith. 2015. Comparison of pharmacokinetics and milk elimination of flunixin in healthy cows and cows with mastitis. J. Am. Vet. Med. Assoc. 246:118-125.

Neveux, S., D. M. Weary, J. Rushen, M. A. G. von Keyserlingk, and A. M. de Passille. 2006. Hoof discomfort changes how dairy cattle distribute their body weight. J. Dairy Sci. 89:2503-2509.

O'Callaghan, K. A., P. J. Cripps, D. Y. Downham, and R. D. Murray. 2003. Subjective and objective assessment of pain and discomfort due to lameness in dairy cattle. Anim. Welf. 12:605-610.

Pastell, M. E., and M. Kujala. 2007. A probabilistic neural network model for lameness detection. J. Dairy Sci. 90:2283-2292.

Rushen, J., E. Pombourcq, and A. M. de Passillé. 2007. Validation of two measures of lameness in dairy cows. Appl. Anim. Behav. Sci 106:173-177.

Shearer, J. K., M. L. Stock, S. R. Van Amstel, and J. F. Coetzee. 2013. Assessment and management of pain associated with lameness in cattle. Vet. Clin. North Am. Food Anim. Pract. 29:135-156.

Solano, L., H. W. Barkema, S. Mason, E. A. Pajor, S. J. LeBlanc, and K. Orsel. 2016. Prevalence and distribution of foot lesions in dairy cattle in Alberta, Canada. J. Dairy Sci. 99:6828-6841.

Sprecher, D. J., D. E. Hostetler, and J. B. Kaneene. 1997. A lameness scoring system that uses posture and gait to predict dairy cattle reproductive performance. Theriogenology 47:1179-1187.

Van Hertem, T., Y. Parmet, M. Steensels, E. Maltz, A. Antler, A. A Schlageter-Tello, C. Lokhorst, C. E. B. Romanini, S. Viazzi, C. Bahr, and D. Berckmans. 2014. The effect of routine hoof trimming on locomotion score, ruminating time, activity, and milk yield of dairy cows. J. Dairy Sci. 97:4852-4863.

Westin, R., A. Vaughan, A. M. de Passillé, T. J. DeVries, E. A. Pajor, D. Pellerin, and J. Rushen. 2016. Cow- and farm-level risk factors for lameness on dairy farms with automated milking systems. J. Dairy Sci. 99:3732-3743. 